\title{
Craniopharyngioma in children: trends from a third consecutive single-center cohort study
}

\author{
Hani J. Marcus, FRCS, ${ }^{1,2}$ Fahid T. Rasul, FRCS, ${ }^{3}$ Ziad Hussein, MRCP, ${ }^{1,4}$ \\ Stephanie E. Baldeweg, FRCP, ${ }^{1,4}$ Helen A. Spoudeas, FRCP, FRCPCH, ${ }^{3}$ Richard Hayward, FRCS, ${ }^{3}$ \\ Noor ul Owase Jeelani, FRCS, ${ }^{3}$ Dominic Thompson, FRCS, ${ }^{3}$ Joan P. Grieve, MD, FRCS(SN), ${ }^{1}$ \\ Neil L. Dorward, FRCS, ${ }^{1,2}$ and Kristian Aquilina, FRCS ${ }^{3}$
}

\begin{abstract}
1Department of Neurosurgery, National Hospital for Neurology and Neurosurgery, London; ${ }^{2}$ Wellcome/EPSRC Centre for Interventional and Surgical Sciences, University College London; ${ }^{3}$ Great Ormond Street Hospital, London; and ${ }^{4}$ Department of Endocrinology, University College London Hospital, London, United Kingdom
\end{abstract}

\begin{abstract}
OBJECTIVE The management of children with craniopharyngioma has evolved over time, with a trend toward less invasive neurosurgical approaches as surgeons have sought to balance oncological control and treatment-related morbidity. To this end, the aim of this study was to evaluate the safety and effectiveness of the current management of children with craniopharyngioma compared to the previous management methods used at the authors' treatment center.
\end{abstract}

METHODS A prospectively maintained database was searched over a 14-year period between January 1, 2005, and December 31,2018 , to identify all children 17 years of age or younger with a new diagnosis of craniopharyngioma. A retrospective case note review was performed for each child to extract data on the presentation, investigation, treatment, and outcome of their illness. Morbidity was assessed in the same fashion as in previous cohorts, according to the following categories: visual loss, pituitary dysfunction, hypothalamic dysfunction, neurological deficits, and cognitive impairment.

RESULTS In total, 59 children were identified with craniopharyngioma during the study period. A total of 92 operations were performed, including cyst drainage (35/92; 38.0\%), craniotomy and resection (30/92; 32.6\%), and transsphenoidal resection (16/92; 17.4\%). Approximately two-thirds of all operations were performed using image guidance $(66 / 92 ; 71.7 \%)$ and one-third were performed using endoscopy (27/92; 29.3\%). The majority of children had adjuvant therapy comprising proton beam therapy $(18 / 59 ; 30.5 \%)$ or conventional radiotherapy $(16 / 59 ; 27.1 \%)$. The median follow-up duration was 44 months (range 1-142 months), and approximately one-half of the children had no evidence of residual disease on MRI studies $(28 / 59 ; 47.5 \%)$. Of the remaining 31 children, there was a reduction in the volume of residual disease in 8 patients $(8 / 59 ; 13.6 \%)$, stable residual disease in $18(18 / 59 ; 30.5 \%)$, and tumor growth in 5 patients $(5 / 59 ; 8.5 \%)$. There was significantly reduced morbidity $(p<0.05)$ in all categories in the current cohort compared with our last cohort (1996-2004).

CONCLUSIONS The authors' institutional experience of pediatric craniopharyngioma confirms a trend toward less invasive neurosurgical procedures, most of which are now performed with the benefit of image guidance or endoscopy. Moreover, the authors have identified an expanding role for more targeted radiotherapy for children with residual disease. These advances have allowed for tumor control comparable to that achieved in previous cohorts, but with significantly reduced morbidity and mortality.

https://thejns.org/doi/abs/10.3171/2019.10.PEDS19147

KEYWORDS surgery; craniopharyngioma; endoscopy; image guidance; outcomes; oncology

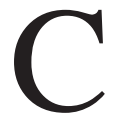

RANIOPHARYNGIOMA is a rare but important intracranial tumor that continues to represent a considerable challenge to the pediatric neurosurgeon. It is defined by the World Health Organization (WHO) histologically as a benign tumor (WHO grade I) but has often been described as behaving in a malignant manner because of its propensity to be located close to highly eloquent brain structures and its propensity for local recurrence. ${ }^{18}$ Both the tumor itself and attempts to treat it can result in considerable visual, endocrine, and cognitive morbidity.

Attitudes of neurosurgeons regarding the management of children with craniopharyngioma have evolved over time, in part reflecting a general trend toward less invasive 

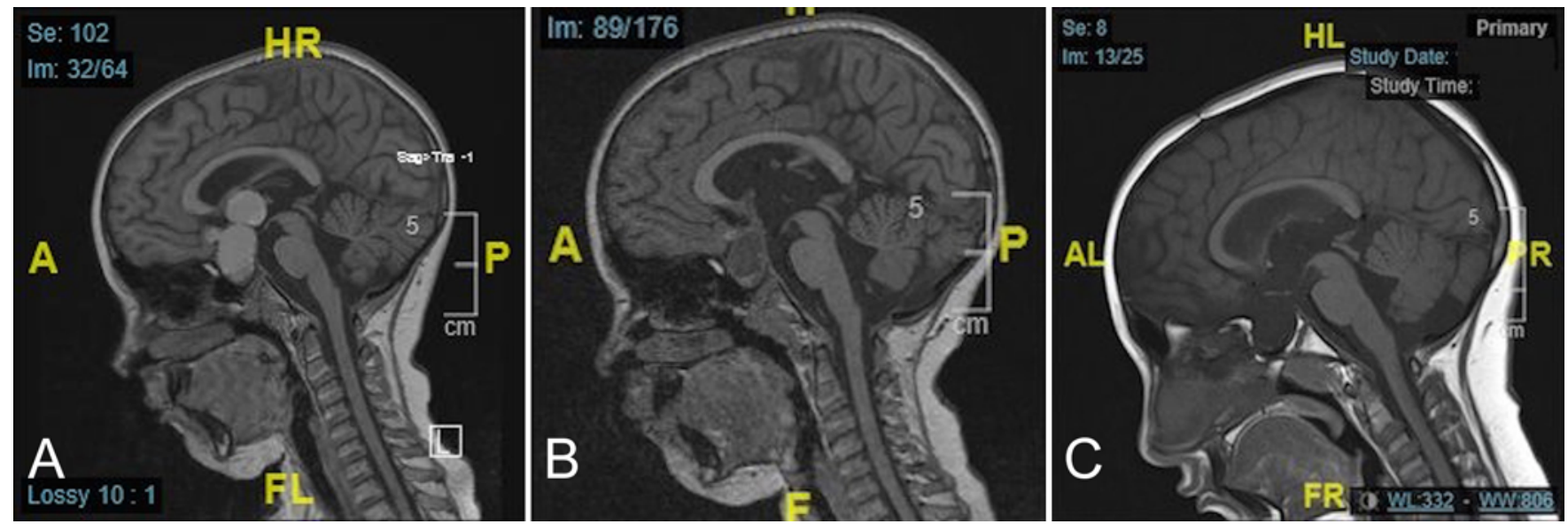

FIG. 1. Illustrative case of an 8-year-old girl who presented with headache, vomiting, and blurred vision. A: Preoperative T1-weighted brain MR image demonstrating sellar and suprasellar craniopharyngioma. B: Postoperative T1-weighted brain MR image following extended transsphenoidal resection of the craniopharyngioma. C: Posttreatment T1-weighted brain MR image following proton beam therapy. Figure is available in color online only.

neurosurgical approaches. ${ }^{31}$ A survey of American pediatric neurosurgeons approximately 20 years ago revealed that the overwhelming majority favored radical surgical resection. ${ }^{32}$ At our own institution, our default management had been to perform radical resection where possible and to reserve radiotherapy for those children whose tumors had been incompletely resected or whose tumors had recurred. In a previous cohort of 75 children who were treated at our institution between 1973 and 1994, the 10year survival rate was $88 \%$. Significant treatment-related morbidity occurred in this cohort, particularly hypothalamic dysfunction, and a $12 \%(9 / 75)$ mortality rate. ${ }^{5}$

In the following decade, we altered our management of children with craniopharyngioma to become more flexible, with an emphasis on reducing morbidity and mortality. In brief, children were stratified at presentation into 2 groups, those in whom it was deemed appropriate to attempt a radical resection and those considered at high risk from radical resection, in whom a subtotal resection or simple cyst aspiration was performed as part of a staged approach, followed by radiotherapy either immediately after or anticipated but deferred by virtue of the child's young age. In the subsequent cohort of 48 children treated between 1996 and 2004, the rate of tumor control was comparable, but the morbidity was significantly lower, and there was a $4 \%(2 / 48)$ morality rate. ${ }^{36}$

In the years since, we have continued to refine our management of children with craniopharyngioma, and in particular we have made use of several technological advances, such as image guidance and endoscopy, to facilitate less invasive neurosurgical approaches and proton beam therapy to deliver more targeted radiotherapy. To this end, the aim of this study was to evaluate the safety and effectiveness of our current treatment management strategy for children with craniopharyngioma compared to that used in previous cohorts.

\section{Methods}

The Strengthening the Reporting of Observational
Studies in Epidemiology (STROBE) statement was used in the preparation of this section of the article. ${ }^{40}$

The study was registered as a Service Evaluation Study with the Great Ormond Street Hospital for Children NHS Foundation Trust Clinical Audit Committee and the University College London Hospitals NHS Foundation Trust Clinical Audit Committee. Informed consent was not sought, as this was a retrospective study.

\section{Setting and Participants}

The study was conducted at Great Ormond Street Hospital for Children, which acts as the regional referral center in North London for children with brain tumors, and the National Hospital for Neurology and Neurosurgery, where most of our patients are transitioned for continuing care once they enter adulthood.

Our current management of children with craniopharyngioma is modified according to their clinical presentation and imaging features but generally includes a combination of surgical resection and radiotherapy (Fig. 1).

Each case is managed jointly by the surgical and medical teams, which include endocrinologists, ophthalmologists, and radiation oncologists. Before surgery, each case is discussed in a dedicated multidisciplinary meeting, and a decision is then made on the surgical approach. The primary procedure, where applicable, is drainage of large cystic components, and thereafter the decision to proceed with radical surgical resection is dependent on clinical and radiological features. Children who demonstrate hypothalamic dysfunction at presentation are more likely to be found to have involvement of the hypothalamus on imaging; we are reluctant to attempt complete resection in these cases. De Vile et al. reported the association of obesity with preoperative hypothalamic involvement evident on MR images. ${ }^{4}$ Absence of the pituitary stalk, displacement of the optic chiasm, and peritumoral hypothalamic edema are all known to be associated with preoperative hyperphagia and obesity. ${ }^{24}$ Acute hydrocephalus is also a predictor of hypothalamic involvement. ${ }^{7,25}$ The relationship of the tu- 
mor to the walls of the third ventricle, best seen in the coronal plane, defines hypothalamic involvement; increased signal changes on T2-weighted and FLAIR sequence MR images, as well as contrast enhancement, predict increased hypothalamic risk. ${ }^{38}$ Increased risk is also associated with tumors that extend posterior to the mamillary bodies. ${ }^{27} \mathrm{Tu}-$ mors extending into the ventricular system are also known to be associated with increased risk, and those with a retrochiasmatic growth pattern and an incompetent diaphragm are associated with a higher postoperative BMI. ${ }^{24,34}$

In addition to clinical and anatomical factors, our decision to proceed with radical resection is also influenced by scoring systems that were published during the time this cohort was being treated at our center. ${ }^{26,28}$ These systems attempted to objectively define the degree of hypothalamic involvement and the associated risk of complete resection. On the basis of their 66 pediatric craniopharyngiomas, Puget et al. published a simple 3-point scoring system, based on coronal and sagittal MRI findings, where hypothalamic involvement was classified as grade 0 (no involvement), grade 1 (tumor abutting or displacing the hypothalamus), or grade 2 (hypothalamus significantly involved and no longer identifiable). ${ }^{28}$ In another classification, the location of the tumor was defined as involving one of the following areas: limited superiorly by the diaphragma sellae, below the optic chiasm and mamillary bodies, or above the latter two structures. ${ }^{26}$ This last group is further subdivided into areas anterior and posterior to the mamillary bodies. Involvement of higher and more posterior structures was associated with higher risk.

During surgery, we frequently make use of image guidance and endoscopy, depending on their availability and individual surgeon preference, in an attempt to reduce the risk of injury to the hypothalamus.

Following surgery, each case is rediscussed in the multidisciplinary meeting to consider the pathology findings, clinical progress, and postoperative imaging features. A decision is then made on ongoing management with proton beam radiotherapy, conventional radiotherapy, or simple surveillance with serial imaging.

All cases are recorded in a prospectively maintained database, and for the current study we searched this database over the 14-year period between January 1, 2005, and December 31, 2018, to identify and access the data for all children 17 years of age or younger with a new diagnosis of craniopharyngioma.

\section{Variables and Data Sources}

A retrospective case note review was performed for each child to extract data on their presentation, investigation, treatment, and outcome.

Data on each child's presentation included their age, sex, symptoms, and signs. Data on their investigation included the location and signal characteristics of the craniopharyngioma on MR images and the presence of associated ventriculomegaly. For all children, data on their treatment included both operative and nonoperative interventions and any associated complications. Data on their outcome included evidence of tumor control on postoperative imaging, morbidity, and mortality. Morbidity was assessed in the same fashion as in previous cohorts using the following categories: visual loss, pituitary dysfunction, hypothalamic dysfunction, neurological deficits, and cognitive impairment, as measured at last follow-up (Table 1) ${ }^{36}$ Cognitive impairment was evaluated according to educational requirements, which has the advantage of being easily identified in retrospective analyses. In each category, severity was rated between 0 (best) and 3 (worst).

\section{Study Size and Statistical Methods}

No formal power calculation was performed. Instead, the sample size was determined with a constraint-based pragmatic approach and on the basis of our previous cohort studies. ${ }^{5,36}$ We considered a minimum of 50 children sufficient for meaningful comparison with previous cohorts, and it was estimated that this would be achieved over a 14-year period.

Data were analyzed with SPSS version 20.0 (IBM Corp.). The means and standard deviations were calculated for parametric variables, and the median and interquartile ranges calculated for nonparametric variables. The chi-square test and Fisher's exact test were used to compare categorical variables. A value of $p<0.05$ was considered statistically significant.

\section{Results}

\section{Presentation and Investigation}

In total, 59 children were identified with craniopharyngioma during the study period. The median age was 8.5 years (range $1-17$ years), and the male/female ratio was 1.36:1. The most common presenting symptoms were headache $(33 / 59 ; 55.9 \%)$, vomiting $(25 / 59 ; 42.4 \%)$, and visual loss $(22 / 59 ; 37.2 \%)$. Other common symptoms were related to endocrine dysfunction and included short stature $(14 / 59 ; 23.7 \%)$, lethargy $(11 / 59 ; 18.6 \%)$, and polydipsia and/or polyuria $(8 / 58 ; 13.6 \%)$. Cognitive and behavioral symptoms were rare at presentation $(4 / 59 ; 6.8 \%)$, and in 2 cases the craniopharyngioma was diagnosed incidentally following a minor head injury $(2 / 59 ; 3.4 \%)$.

The most common signs were ophthalmic and included reduced visual acuity in one or both eyes $(37 / 59 ; 62.7 \%)$, papilledema and optic atrophy $(13 / 59 ; 22.0 \%)$, restricted visual fields $(8 / 59 ; 13.6 \%)$, and ophthalmoplegia (6/59; $10.2 \%)$. Other signs included ataxia $(8 / 59 ; 13.6 \%)$ and a reduced level of consciousness $(2 / 59 ; 3.4 \%)$.

The most common location for craniopharyngioma was suprasellar $(38 / 59 ; 64.4 \%)$; in 4 of these cases the tumor extended into the third ventricle, in 2 cases into the posterior fossa, and in 1 case into the anterior fossa. In the remaining cases the craniopharyngioma was located in both the sellar and suprasellar regions $(14 / 59 ; 23.7 \%)$ or within the sellar region alone $(7 / 59 ; 11.9 \%)$. In approximately one-fifth of cases the craniopharyngioma appeared cystic $(12 / 59 ; 20.3 \%)$, and a similar proportion appeared calcified $(9 / 59 ; 15.3 \%)$. There was associated ventriculomegaly in 24 cases $(24 / 59 ; 40.7 \%)$.

\section{Treatment}

A total of 92 operations were performed in the 59 children. Overall, these operations were less invasive than those performed in previous cohorts (Fig. 2). The most 
TABLE 1. Grading system used to assess morbidity

\begin{tabular}{|c|c|}
\hline Category and Grades* & Description \\
\hline \multicolumn{2}{|l|}{ Visual loss } \\
\hline 3 & Visual acuity $<6 / 60$ in both eyes \\
\hline 2 & Visual acuity $6 / 18$ to $6 / 60$ in both eyes or $<6 / 60$ in 1 eye \\
\hline 1 & Visual acuity $6 / 9$ to $>6 / 18$ in 1 or both eyes \\
\hline 0 & Normal \\
\hline \multicolumn{2}{|l|}{ Pituitary dysfunction } \\
\hline 3 & Panhypopituitarism and impaired thirst \\
\hline 2 & Panhypopituitarism \\
\hline 1 & Partial anterior hypopituitarism and/or diabetes insipidus \\
\hline 0 & Normal \\
\hline \multicolumn{2}{|l|}{ Hypothalamic dysfunction } \\
\hline 3 & $\begin{array}{l}\text { Severe hypothalamic syndrome with extreme obesity and change in affect or behavior and other } \\
\text { clinical manifestations, e.g., impaired thirst }\end{array}$ \\
\hline 2 & Moderate hypothalamic syndrome with obesity and change in affect or behavior \\
\hline 1 & Mild hypothalamic syndrome with obesity but no change in affect or behavior \\
\hline 0 & Normal \\
\hline \multicolumn{2}{|l|}{ Neurological deficits } \\
\hline 3 & Severe motor deficit and epilepsy \\
\hline 2 & Mild to moderate motor deficit \\
\hline 1 & Signs only \\
\hline 0 & Normal \\
\hline \multicolumn{2}{|l|}{ Cognitive impairment } \\
\hline 3 & Special school \\
\hline 2 & Normal school but with assistance \\
\hline 1 & Normal school with educational concerns but no assistance \\
\hline 0 & Normal school and no educational concerns \\
\hline
\end{tabular}

common operation was cyst drainage $(35 / 92 ; 38.0 \%)$, and in most of these cases a reservoir was left to allow access postoperatively $(30 / 92 ; 32.6 \%)$. The other common operations were craniotomy and resection $(30 / 92 ; 32.6 \%)$ and transsphenoidal resection $(16 / 92 ; 17.4 \%)$. Five children underwent insertion of a ventriculoperitoneal shunt (5/92; 5.4\%). Approximately two-thirds of all operations were performed using image guidance $(66 / 92 ; 71.7 \%)$ and one-third using endoscopy, including transsphenoidal and transventricular approaches $(27 / 92 ; 29.3 \%)$.

Postoperative complications included CSF leak (4/92; $4.3 \%$ ) and wound infection $(3 / 92 ; 3.3 \%)$. One child had a postoperative intracerebral hematoma that required surgical evacuation, 1 child developed hydrocephalus that required a ventriculoperitoneal shunt, and 1 child had seizures that were managed medically. The median length of stay was 10 days (range $1-44$ days).

The majority of children had adjuvant therapy, including proton beam therapy $(18 / 59 ; 30.5 \%)$ or conventional radiotherapy $(16 / 59 ; 27.1 \%)$, typically 50 Gy in 30 fractions. Three children had interferon- $\alpha$ therapy for cystic recurrence.

Posttherapy complications occurred in 1 child, who developed vasculopathy following proton beam therapy.

\section{Outcome}

The median follow-up was 44 months (range 1-142 months). The actuarial progression-free survival curve for the current cohort (2005-2018) is illustrated in Fig. 3, and the overall 10-year progression-free survival was estimated to be $68.8 \%$. At last follow-up, approximately one-half of the children had no evidence of residual disease on MRI $(28 / 59 ; 47.5 \%)$. In the remaining 31 children, there was a reduction in the volume of residual disease in 8 children $(8 / 59 ; 13.6 \%)$, stable residual disease in $18(18 / 59 ; 30.5 \%)$, and tumor growth in 5 children $(5 / 59 ; 8.5 \%)$.

One child with growth of residual disease died, and this child's death was thought to be due to tumor progression $(1 / 59 ; 1.7 \%)$. The other 4 children with growth of residual disease remain under active management.

Cases of visual loss, pituitary dysfunction, hypothalamic dysfunction, neurological deficits, and cognitive impairment occurring before and after treatment in all cohorts are summarized in Table 2 and Fig. 4. Visual loss was significantly less likely to occur after treatment than before treatment, whereas pituitary dysfunction was more likely to occur after treatment ( $p<0.01$ in both cases).

In the current cohort there was an obvious trend toward 
2005 to 2018 cohort

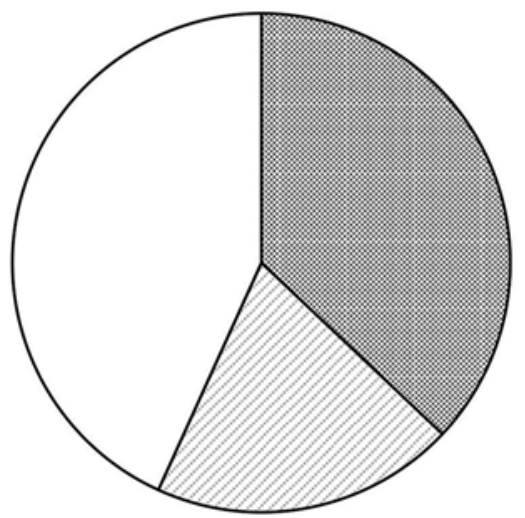

1996 to 2004 cohort

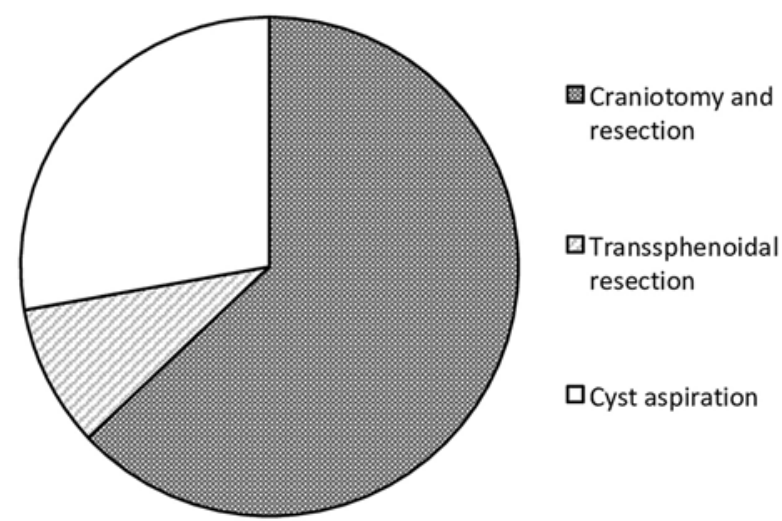

FIG. 2. Chart illustrating the varying number of cyst aspirations, transsphenoidal resections, and craniotomy and resections in the 2005-2018 and the 1996-2004 cohorts.

reduced morbidity in all categories compared to our previous cohorts. Before treatment, the rates of visual loss, pituitary dysfunction, hypothalamic dysfunction, neurological deficits, and cognitive impairment were similar to those in the last cohort (1996-2004; p > 0.1 in all cases). After treatment, however, the rates of visual loss, pituitary dysfunction, hypothalamic dysfunction, neurological deficits, and cognitive impairment were all significantly reduced in the current cohort compared with the previous cohort $(\mathrm{p}<$ 0.05 in all cases).

\section{Discussion}

\section{Principal Findings}

In our most current cohort of children with craniopharyngioma, we have confirmed a clear and growing trend toward the use of less invasive neurosurgical procedures, most of which are now performed with the benefit of image guidance or endoscopy. Moreover, there is an expanding role for more targeted radiotherapy for children with residual disease. These advances have allowed for tumor control comparable to that obtained in our previous cohorts, but with significantly reduced morbidity and mortality.

\section{Comparison With Other Studies}

Our findings of a trend toward less invasive neurosurgical procedures and increased use of image guidance or endoscopy are in keeping with the literature. In a recent analysis of patents and peer-reviewed publications within neurosurgery, we found that image guidance and endoscopy were among the top 5 performing technology clusters over the last 50 years.22 We speculate that the increased availability and familiarity of image guidance and endoscopy during the treatment period of the cohort reported here allowed for more frequent cyst drainage and transsphenoidal resection, respectively, in this cohort than in our previous patient cohorts.

The use of image guidance in neurosurgery has been promulgated since the development of frameless techniques in the 1980s and 1990s. ${ }^{19,30}$ Image guidance has two distinct roles in neurosurgery: first, to better define the surgical approach; and second, to allow for unambiguous tissue dissection, particularly in the context of tumor resection. Currently, image guidance platforms are largely used for the former, and several groups have reported their use to facilitate less invasive neurosurgical approaches when managing the treatment of children with craniopharyngioma and other skull base tumors., ${ }^{92,14,16,17,39}$ Although image guidance was used in approximately two-thirds of all operations in our current cohort, it was used for almost all operations in the latter years, and we now consider it a standard of care. In the near future, intraoperative imaging with ultrasound, CT, or MRI may routinely allow for an increased extent of tumor resection, while preserving highly eloquent brain structures, and this is already the case in many centers. ${ }^{8,11,23}$

The use of endoscopy in neurosurgery has also increased since the development of the SELFOC lens (Go!Foton), charge-coupled device (CCD), and fiber-optic light source in the 1980s..$^{10}$ Endoscopy allows for an improved viewing angle, higher magnification, and increased

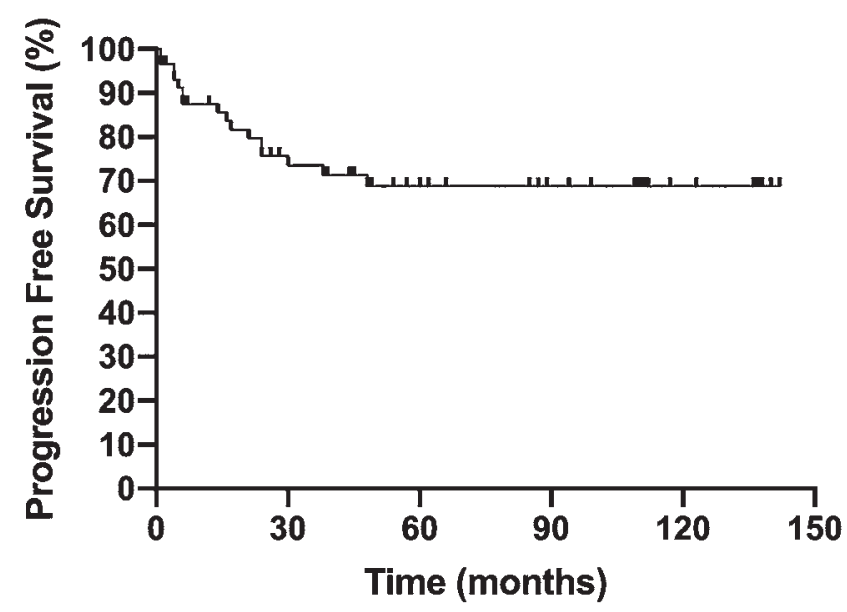

FIG. 3. Kaplan-Meier curve illustrating the actuarial progression-free survival for the present cohort (2005-2018). Time was measured from the initial surgery. Recurrence was determined by postoperative imaging. 
TABLE 2. Morbidity before and after treatment in the present and previous cohorts

\begin{tabular}{|c|c|c|c|c|c|}
\hline Grade $^{*}$ & Visual Loss & Pituitary Dysfunction & Hypothalamic Dysfunction & Neurological Deficits & Cognitive Impairment \\
\hline \multicolumn{6}{|c|}{ Before treatment (2005-2018 cohort) } \\
\hline 3 & $5(8)$ & $0(0)$ & $0(0)$ & $0(0)$ & $4(7)$ \\
\hline 1 & $19(32)$ & $25(42)$ & $7(12)$ & $4(7)$ & $1(2)$ \\
\hline 0 & $22(37)$ & $33(56)$ & $49(83)$ & $55(93)$ & $54(92)$ \\
\hline \multicolumn{6}{|c|}{ After treatment (2005-2018 cohort) } \\
\hline 2 & $3(5)$ & $10(17)$ & $2(3)$ & $0(0)$ & $1(2)$ \\
\hline 1 & $0(0)$ & $26(44)$ & $7(12)$ & $4(7)$ & $7(12)$ \\
\hline 0 & $53(90)$ & $23(39)$ & $49(83)$ & $55(93)$ & $49(83)$ \\
\hline \multicolumn{6}{|c|}{ After treatment (1996-2004 cohort) } \\
\hline 3 & $9(20)$ & $2(4)$ & $5(10)$ & $3(6)$ & $3(6)$ \\
\hline \multicolumn{6}{|c|}{ After treatment (1973-1994 cohort) } \\
\hline 3 & $11(15)$ & $10(13)$ & $12(16)$ & $17(23)$ & $20(27)$ \\
\hline 2 & $29(39)$ & $57(76)$ & $10(13)$ & $13(17)$ & $10(13)$ \\
\hline 1 & $11(15)$ & $7(9)$ & $20(27)$ & $20(27)$ & $17(23)$ \\
\hline 0 & $24(32)$ & $1(1)$ & $33(44)$ & $25(23)$ & $28(37)$ \\
\hline
\end{tabular}

Values are presented as number (\%) of patients.

* Grading based on information found in Thompson D, Phipps K, Hayward R: Craniopharyngioma in childhood: our evidence-based approach to management. Childs Nerv Syst 21:660-668, 2005.

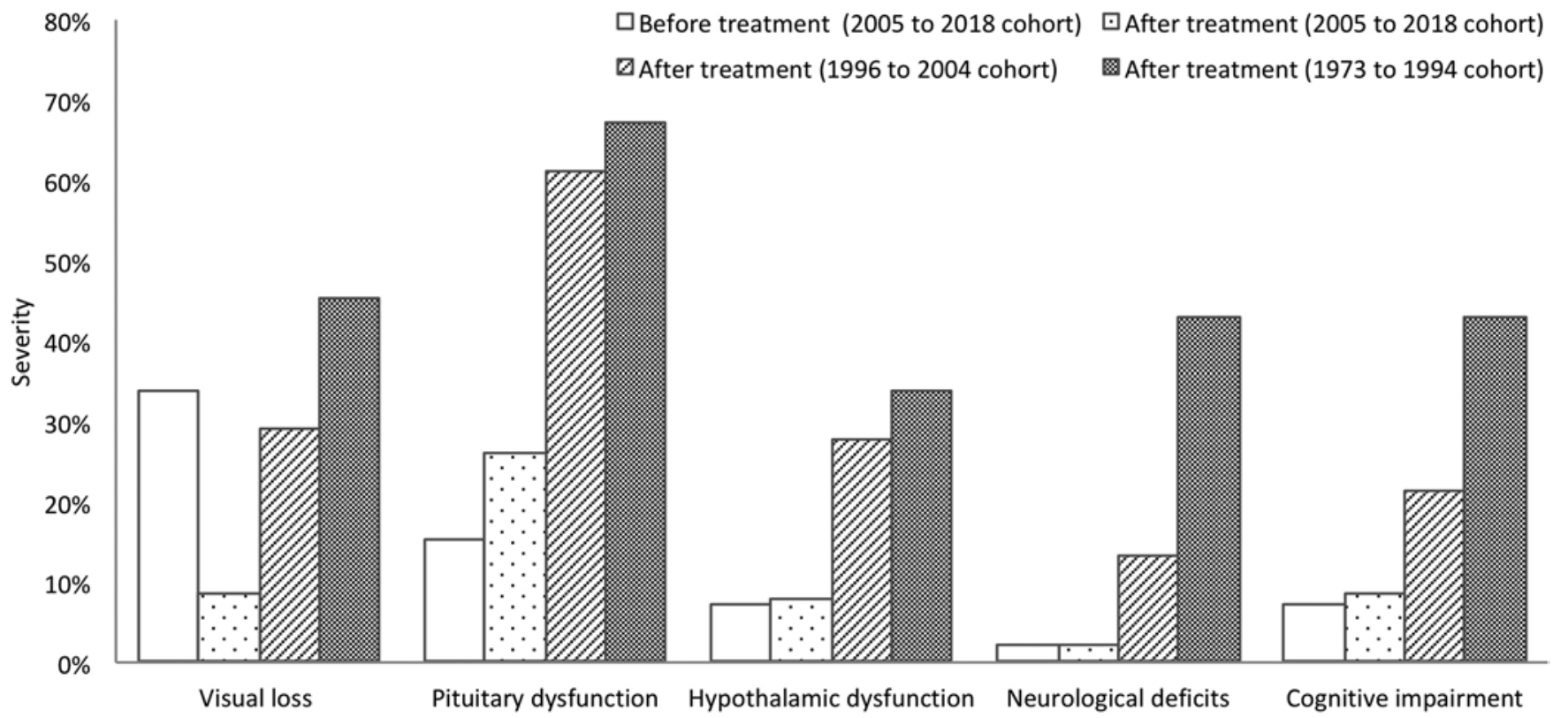

FIG. 4. Graph illustrating morbidity before and after treatment, in the present (2005-2018) and previous (1973-1994 and 1996-2004) cohorts. In each category, the severity is reported as a proportion of the maximum possible score $(0 \%=$ no patients have any morbidity; $100 \%$ = all patients have maximal morbidity). 
illumination during operations performed through a narrow surgical corridor, making this technology ideally suited to the management of deep-seated tumors such as craniopharyngioma. A number of groups have reported the use of the endoscopic intraventricular and endoscopic endonasal transsphenoidal approaches when managing children with craniopharyngioma. ${ }^{2,6,12,14,16,17}$ Advances such as 3D and high-definition endoscopy may further improve visualization in the coming years. ${ }^{21}$

Alongside the aforementioned trend toward the use of less invasive neurosurgical procedures when managing children with craniopharyngioma, there has also been a trend toward the use of more targeted radiotherapy, including proton beam therapy. There remains limited evidence in the literature from comparisons of proton beam radiotherapy with external beam radiotherapy used in the treatment of these patients. Nonetheless, several retrospective studies have suggested that proton beam radiotherapy is at least as safe and effective as external beam therapy, and that worldwide a growing number of children are being treated at proton centers. ${ }^{1,15,41}$

The overall outcome of our new, less invasive treatment management paradigm has been a significant reduction in morbidity and mortality rates in our current cohort compared with our previous cohorts of children with craniopharyngioma, while maintaining good tumor control rates. These findings are consistent with other reports in the literature. In a recent systematic review, Clark et al. identified 109 studies reporting the outcomes of 531 children who underwent treatment for craniopharyngioma and concluded that gross-total resection was associated with increased risk of endocrine dysfunction and neurological deficits compared to subtotal resection and radiotherapy. ${ }^{3}$

Our treatment-related morbidity and mortality rates compare favorably to those reported for other high-volume centers. In a recent narrative review, Müller found that following treatment the rate of permanent diabetes insipidus was reported to be between $40 \%$ and $93 \%$ and the rate of growth hormone deficiency was between $70 \%$ and $92 \%$, compared with a rate of $61 \%$ for pituitary dysfunction in our current cohort..$^{25}$ The rate of morbidities associated with hypothalamic dysfunction, such as obesity, was also found to be high in other centers, reaching up to $55 \%$, compared with $17 \%$ in our current cohort. ${ }^{25}$ Similarly, the reported rate of neurological deficits such as hemiparesis was reported to be $8 \%$, and that for cognitive impairment was $18 \%$, compared with rates of $7 \%$ and $17 \%$, respectively, in our current cohort. 25

Other centers that have adopted patient management paradigms analogous to ours and have taken great care to spare the hypothalamus have reported similarly favorable outcomes. Puget et al. reported no new cases of hyperphagia, morbid obesity, or behavioral dysfunction in a cohort of 22 children..$^{28}$ Mallucci et al. also reported no new cases of hyperphagia or morbid obesity in a cohort of 20 patients. ${ }^{20}$

At last follow-up, 91.5\% (54/59) of our current cohort of children with craniopharyngioma had no or stable residual disease found on MRI studies. The remaining 5 children showed tumor progression, and tumor-related death occurred in one of these patients. Other centers have also achieved good tumor control rates after subtotal resection when followed by contemporary radiotherapy. Stripp et al. reported that $84 \%$ of children and young adults had tumor control at 10 years following subtotal resection and radiotherapy compared to only $42 \%$ following subtotal resection alone. ${ }^{35}$ Karavitaki et al. reported that $77 \%$ of patients had tumor control at 10 years following subtotal resection and radiotherapy compared to $38 \%$ following subtotal resection alone. ${ }^{13}$ Schoenfeld et al. reported that $73 \%$ of patients had tumor control at 2 years following subtotal resection and radiotherapy compared with $36 \%$ following subtotal resection alone..$^{33}$

\section{Limitations}

The present study has several limitations. Morbidity was assessed in the same fashion as in our previous cohorts but our reported results were less detailed than those reported by other groups; nevertheless, our findings allowed for meaningful comparison of our current cohort to our previous cohorts. The median follow-up of 44 months in our patients was short, in part due to the fact that many of our patients transition to other hospitals once they enter adulthood, but did allow for evaluation of tumor control on postoperative imaging and morbidity and mortality after treatment. The sample size of 59 children was small because craniopharyngioma is rare, but nonetheless met our a priori minimum of 50 children.

More generally, although the cases were recorded on a prospectively maintained database, the data were drawn from a retrospective case note review and were therefore liable to inherent disadvantages such as incomplete or inaccurate data, selection bias, and lack of control.

\section{Conclusions}

Survival rates for craniopharyngioma are good, with the majority of children expected to reach adulthood. However, despite its benign histology the treatment-related morbidity for craniopharyngioma and the propensity for local tumor recurrence have meant that hitherto many children have faced a lifetime of medical and neurosurgical intervention.

Our third consecutive cohort of children with craniopharyngioma confirms a trend toward less invasive neurosurgical procedures and more targeted radiotherapy. This trend is associated with considerable reductions in morbidity and mortality following treatment, while maintaining good tumor control rates.

Now and in the coming years, our focus will be on maintaining acceptable rates of morbidity and mortality, while increasing the effectiveness of treatment, particularly for children with tumors that involve critical structures such as the hypothalamus, or appear to have a particular biological propensity for recurrence. We speculate that innovative treatments such as targeted medical therapy ${ }^{37}$ and high-intensity focused ultrasound (HIFU ${ }^{29}$ may play roles in achieving this goal, alongside continued refinement of our management paradigm.

\section{Acknowledgments}

The authors received no specific funding for this work. Hani 
J. Marcus is supported by the Wellcome/EPSRC Centre for Interventional and Surgical Sciences (WEISS) (203145Z/16/Z).

\section{References}

1. Bishop AJ, Greenfield B, Mahajan A, Paulino AC, Okcu MF, Allen PK, et al: Proton beam therapy versus conformal photon radiation therapy for childhood craniopharyngioma: multi-institutional analysis of outcomes, cyst dynamics, and toxicity. Int J Radiat Oncol Biol Phys 90:354-361, 2014

2. Cappabianca P, Cavallo LM, Esposito F, De Divitiis O, Messina A, De Divitiis E: Extended endoscopic endonasal approach to the midline skull base: the evolving role of transsphenoidal surgery. Adv Tech Stand Neurosurg 33:151-199, 2008

3. Clark AJ, Cage TA, Aranda D, Parsa AT, Auguste KI, Gupta $\mathrm{N}$ : Treatment-related morbidity and the management of pediatric craniopharyngioma: a systematic review. J Neurosurg Pediatr 10:293-301, 2012

4. de Vile CJ, Grant DB, Hayward RD, Kendall BE, Neville BG, Stanhope R: Obesity in childhood craniopharyngioma: relation to post-operative hypothalamic damage shown by magnetic resonance imaging. J Clin Endocrinol Metab 81:2734-2737, 1996

5. De Vile CJ, Grant DB, Kendall BE, Neville BG, Stanhope R, Watkins KE, et al: Management of childhood craniopharyngioma: can the morbidity of radical surgery be predicted? J Neurosurg 85:73-81, 1996

6. Delitala A, Brunori A, Chiappetta F: Purely neuroendoscopic transventricular management of cystic craniopharyngiomas. Childs Nerv Syst 20:858-862, 2004

7. DeVile CJ, Grant DB, Hayward RD, Stanhope R: Growth and endocrine sequelae of craniopharyngioma. Arch Dis Child 75:108-114, 1996

8. Giordano M, Samii A, Lawson McLean AC, Bertalanffy H, Fahlbusch R, Samii M, et al: Intraoperative magnetic resonance imaging in pediatric neurosurgery: safety and utility. $\mathbf{J}$ Neurosurg Pediatr 19:77-84, 2017

9. Hayhurst C, Williams D, Yousaf J, Richardson D, Pizer B, Mallucci C: Skull base surgery for tumors in children: longterm clinical and functional outcome. J Neurosurg Pediatr 11:496-503, 2013

10. Hellwig D, Tirakotai W, Riegel T, Heinze S, Bertalanffy H: Endoscopy in neurosurgery. Dtsch Arztebl 104:185-191, 2007

11. Hofmann BM, Nimsky C, Fahlbusch R: Benefit of 1.5-T intraoperative MR imaging in the surgical treatment of craniopharyngiomas. Acta Neurochir (Wien) 153:1377-1390, 2011

12. Jane JA Jr, Prevedello DM, Alden TD, Laws ER Jr: The transsphenoidal resection of pediatric craniopharyngiomas: a case series. J Neurosurg Pediatr 5:49-60, 2010

13. Karavitaki N, Cudlip S, Adams CB, Wass JA: Craniopharyngiomas. Endocr Rev 27:371-397, 2006

14. Kim K, Yeon JY, Seol HJ, Shin HJ: Transventricular endoscopic biopsy of suprasellar tumors: a pediatric case series. Childs Nerv Syst 29:1285-1291, 2013

15. Laffond C, Dellatolas G, Alapetite C, Puget S, Grill J, Habrand JL, et al: Quality-of-life, mood and executive functioning after childhood craniopharyngioma treated with surgery and proton beam therapy. Brain Inj 26:270-281, 2012

16. Leng LZ, Greenfield JP, Souweidane MM, Anand VK, Schwartz TH: Endoscopic, endonasal resection of craniopharyngiomas: analysis of outcome including extent of resection, cerebrospinal fluid leak, return to preoperative productivity, and body mass index. Neurosurgery 70:110-124, 2012

17. Locatelli D, Massimi L, Rigante M, Custodi V, Paludetti G, Castelnuovo P, et al: Endoscopic endonasal transsphenoidal surgery for sellar tumors in children. Int J Pediatr Otorhinolaryngol 74:1298-1302, 2010
18. Louis DN, Perry A, Reifenberger G, von Deimling A, Figarella-Branger D, Cavenee WK, et al: The 2016 World Health Organization Classification of Tumors of the Central Nervous System: a summary. Acta Neuropathol 131:803-820, 2016

19. Maciunas RJ, Galloway RL Jr, Fitzpatrick JM, Mandava VR, Edwards CA, Allen GS: A universal system for interactive image-directed neurosurgery. Stereotact Funct Neurosurg 58:108-113, 1992

20. Mallucci C, Pizer B, Blair J, Didi M, Doss A, Upadrasta S, et al: Management of craniopharyngioma: the Liverpool experience following the introduction of the CCLG guidelines. Introducing a new risk assessment grading system. Childs Nerv Syst 28:1181-1192, 2012

21. Marcus HJ, Hughes-Hallett A, Cundy TP, Di Marco A, Pratt $\mathrm{P}$, Nandi D, et al: Comparative effectiveness of 3-dimensional vs 2-dimensional and high-definition vs standard-definition neuroendoscopy: a preclinical randomized crossover study. Neurosurgery 74:375-381, 2014

22. Marcus HJ, Hughes-Hallett A, Kwasnicki RM, Darzi A, Yang GZ, Nandi D: Technological innovation in neurosurgery: a quantitative study. J Neurosurg 123:174-181, 2015

23. Marcus HJ, Vercauteren T, Ourselin S, Dorward NL: Intraoperative ultrasound in patients undergoing transsphenoidal surgery for pituitary adenoma: systematic review [corrected]. World Neurosurg 106:680-685, 2017

24. Mortini P, Gagliardi F, Bailo M, Spina A, Parlangeli A, Falini A, et al: Magnetic resonance imaging as predictor of functional outcome in craniopharyngiomas. Endocrine 51:148-162, 2016

25. Müller HL: Childhood craniopharyngioma: treatment strategies and outcomes. Expert Rev Neurother 14:187-197, 2014

26. Müller HL: Preoperative staging in childhood craniopharyngioma: standardization as a first step towards improved outcome. Endocrine 51:1-3, 2016

27. Müller HL, Gebhardt U, Teske C, Faldum A, Zwiener I, Warmuth-Metz M, et al: Post-operative hypothalamic lesions and obesity in childhood craniopharyngioma: results of the multinational prospective trial KRANIOPHARYNGEOM 2000 after 3-year follow-up. Eur J Endocrinol 165:17-24, 2011

28. Puget S, Garnett M, Wray A, Grill J, Habrand JL, Bodaert N, et al: Pediatric craniopharyngiomas: classification and treatment according to the degree of hypothalamic involvement. J Neurosurg 106 (1 Suppl):3-12, 2007

29. Quadri SA, Waqas M, Khan I, Khan MA, Suriya SS, Farooqui M, et al: High-intensity focused ultrasound: past, present, and future in neurosurgery. Neurosurg Focus 44(2):E16, 2018

30. Roberts DW, Strohbehn JW, Hatch JF, Murray W, Kettenberger $\mathrm{H}$ : A frameless stereotaxic integration of computerized tomographic imaging and the operating microscope. $\mathbf{J}$ Neurosurg 65:545-549, 1986

31. Sainte-Rose C, Puget S, Wray A, Zerah M, Grill J, Brauner $\mathrm{R}$, et al: Craniopharyngioma: the pendulum of surgical management. Childs Nerv Syst 21:691-695, 2005

32. Sanford RA: Craniopharyngioma: results of survey of the American Society of Pediatric Neurosurgery. Pediatr Neurosurg 21 (Suppl 1):39-43, 1994

33. Schoenfeld A, Pekmezci M, Barnes MJ, Tihan T, Gupta N, Lamborn KR, et al: The superiority of conservative resection and adjuvant radiation for craniopharyngiomas. J Neurooncol 108: 133-139, 2012

34. Steňo J, Bízik I, Steňo A, Matejčík V: Craniopharyngiomas in children: how radical should the surgeon be? Childs Nerv Syst 27:41-54, 2011

35. Stripp DC, Maity A, Janss AJ, Belasco JB, Tochner ZA, Goldwein JW, et al: Surgery with or without radiation therapy in the management of craniopharyngiomas in children and young adults. Int J Radiat Oncol Biol Phys 58:714-720, 2004 
36. Thompson D, Phipps K, Hayward R: Craniopharyngioma in childhood: our evidence-based approach to management. Childs Nerv Syst 21:660-668, 2005

37. Tritos NA: Is there a role for targeted medical therapies in patients with craniopharyngiomas? Future Oncol 11:32213223, 2015

38. Van Gompel JJ, Nippoldt TB, Higgins DM, Meyer FB: Magnetic resonance imaging-graded hypothalamic compression in surgically treated adult craniopharyngiomas determining postoperative obesity. Neurosurg Focus 28(4):E3, 2010

39. van Lindert EJ, Ingels K, Mylanus E, Grotenhuis JA: Variations of endonasal anatomy: relevance for the endoscopic endonasal transsphenoidal approach. Acta Neurochir (Wien) 152:1015-1020, 2010

40. von Elm E, Altman DG, Egger M, Pocock SJ, Gøtzsche PC, Vandenbroucke JP: The Strengthening the Reporting of Observational Studies in Epidemiology (STROBE) statement: guidelines for reporting observational studies. Lancet 370:1453-1457, 2007

41. Winkfield KM, Linsenmeier C, Yock TI, Grant PE, Yeap BY, Butler WE, et al: Surveillance of craniopharyngioma cyst growth in children treated with proton radiotherapy. Int $\mathbf{J}$ Radiat Oncol Biol Phys 73:716-721, 2009

\section{Disclosures}

The authors report no conflict of interest concerning the materials or methods used in this study or the findings specified in this paper.

\section{Author Contributions}

Conception and design: Baldeweg, Spoudeas, Hayward, Jeelani, Thompson, Grieve, Dorward, Aquilina. Acquisition of data: Marcus, Rasul, Hussein. Analysis and interpretation of data: Marcus, Rasul, Hussein. Drafting the article: Marcus, Rasul, Hussein. Critically revising the article: Baldeweg, Spoudeas, Hayward, Jeelani, Thompson, Grieve, Dorward, Aquilina.

\section{Supplemental Information}

\section{Previous Presentations}

The findings of this paper were presented at the 47th Annual Meeting of the International Society of Pediatric Neurosurgery, Birmingham, United Kingdom, October 20-24, 2019.

\section{Correspondence}

Hani J. Marcus: Wellcome/EPSRC Centre for Interventional and Surgical Sciences, London, United Kingdom. h.marcus@ucl. ac.uk. 